\title{
Mitochondrial diversity and the origin of Iberian sheep
}

\author{
Susana PEDRosA ${ }^{\mathrm{a}}$, Juan-José ARRANZ ${ }^{\mathrm{a}}$, Nuno BRITO ${ }^{\mathrm{b}}$, \\ Antonio MOLINA ${ }^{\mathrm{c}}$, Fermín SAN PRIMITIVO ${ }^{\mathrm{a}}$, Yolanda BAYÓN ${ }^{\mathrm{a} *}$ \\ ${ }^{a}$ Departamento de Producción Animal, Universidad de León, 24071 León, Spain \\ ${ }^{\mathrm{b}}$ Departamento de Ciências e Recursos Animais, Escola Superior Agrária, Istituto Politecnico \\ Viana do Castelo, Ponte de Lima, Portugal \\ ${ }^{\mathrm{c}}$ Departamento de Genética, Facultad de Veterinaria, Universidad de Córdoba, Spain
}

(Received 17 March 2006; accepted 11 July 2006)

\begin{abstract}
Mitochondrial DNA diversity was analysed in 19 Iberian and six foreign sheep breeds. Three mtDNA lineages (B, A and C) were found in the Iberian sheep, with type B clearly predominating over the others. The results were analysed for each of the morphologically determined breed groups in Iberian sheep: Merino, Entrefino, Churro and Iberian trunks. MtDNA lineage $\mathrm{C}$ was found only in the Iberian trunk composed of Montesina and Ojalada. These two populations had high mtDNA variability, and in the Iberian sheep only Merino Branco had more variation. The other three Merino types studied showed moderate variability, including the most authentic Merino, the Spanish Merino. These three Merinos clustered closely in a multidimensional scaling representation of distances, while the fourth breed (Merino Branco) showed a clear separation. As for the other two trunks, breeds from the Churro group showed greater maternal uniformity while results for populations included in the so-called Entrefino trunk seemed to have a more heterogeneous maternal origin. The results obtained are discussed with available data from nuclear markers and with morphological classifications, and all this information is analysed in relation to the origin of the different Iberian sheep breeds.
\end{abstract}

mitochondrial DNA / local sheep / sheep origin

\section{INTRODUCTION}

Modern Iberian livestock breeds are the result of influences from multiple and successive invasions throughout history. Sheep originated in Asia, spread into Europe and are thought to have reached the Iberian Peninsula as early as 5000 BCE [16]. A second large ovine immigration came with the Celtic invasions of about 700 BCE. Later influences were brought in by other civilizations such as Phoenicians, Greeks, Romans and, later, the Moors, who reached the

*Corresponding author: yolanda.bayon@unileon.es 
Iberian Peninsula by 711 AD and stayed for a long period close to 800 years. Merinos are the best known among Iberian sheep and their presence in the Peninsula is dated at least $c$. 300-200 BCE on the basis of archaeological findings of ovine votive offerings showing the characteristic Merino wavy wool (National Archaeological Museum, Madrid, Spain).

Traditionally the Iberian sheep have been classified into four main types of trunks mainly based on their wool types. The Merino trunk is the best known among Iberian sheep due to their fine wool. The Churro (coarse) trunk includes coarse-wool sheep distributed mainly throughout the north and centre of the Iberian Peninsula. The Entrefino (medium-fine) type is considered by some authors to be the result of Churro $\times$ Merino crossings, on the basis of its wool of medium thickness, although other opinions [17] suggest an independent origin for this trunk. Finally, the term Iberian trunk refers to a few coarse wool breeds, with peculiar morphological characteristics and very high rusticity. Although there is no unanimous opinion on its origin, some authors have suggested that they derive from the first ovine arrivals from Asia with scarce later influences [17].

Mitochondrial DNA studies have proven very useful for the analysis of the maternal origin of populations (reviewed by Bruford et al. [4]), on the basis of its peculiar characteristics such as maternal inheritance, absence of recombination and quite rapid mutation rate. In sheep, mtDNA investigation has recently allowed for the identification of two new maternal lineages $[8,13,20]$ in addition to the two previously reported types $[9,21]$, which indicates multiphyletic origins for modern breeds; and further recent information about mtDNA variability in sheep is also available with certain data concerning Iberian sheep [11, 14].

Several studies have been made on the genetic diversity of Iberian sheep at a nuclear level to clarify the relationships between breeds and trunks e.g. [1,2]. The aim of the present study was to analyse mitochondrial DNA diversity in Iberian domestic sheep, focussing on the variability at both levels (within breeds and within each of the recognised groups of breeds, or trunks). The final purpose of the study was to supply information which might help to clarify the origin of modern Iberian sheep.

\section{MATERIALS AND METHODS}

\subsection{Animals}

A total of 501 animals were analysed, representing 19 Iberian sheep breeds and six foreign ones (see Tab. I). Unrelated animals were sampled from 3 to 
Table I. Number of sequences $(\mathrm{N})$, nucleotide diversity $(\pi)$, number of haplotypes $(\mathrm{nh})$, haplotype diversity $(\mathrm{Hd})$, number of polymorphic sites $(S)$ and frequency of mtDNA types.

\begin{tabular}{|c|c|c|c|c|c|c|c|c|}
\hline & $\mathrm{N}$ & $\pi$ & $\mathrm{nh}$ & $\mathrm{Hd}$ & $S$ & $\begin{array}{l}\text { mtDNA } \\
\text { type A }\end{array}$ & $\begin{array}{l}\text { mtDNA } \\
\text { type B }\end{array}$ & $\begin{array}{l}\text { mtDNA } \\
\text { type C }\end{array}$ \\
\hline \multicolumn{9}{|l|}{ CHURRO TRUNK } \\
\hline Chu. Ga. Bragançana & 16 & 0.0061 & 15 & 0.995 & 15 & - & 1 & - \\
\hline Churra & 29 & 0.0067 & 28 & 0.995 & 31 & - & 1 & - \\
\hline Churra Lebrijana & 14 & 0.0061 & 11 & 0.945 & 12 & - & 1 & - \\
\hline Latxa & 29 & 0.0047 & 18 & 0.899 & 23 & - & 1 & - \\
\hline Xalda & 24 & 0.0068 & 18 & 0.967 & 22 & - & 1 & - \\
\hline \multicolumn{9}{|l|}{ ENTREFINO TRUNK } \\
\hline Alcarreña & 30 & 0.0069 & 26 & 0.977 & 41 & - & 1 & - \\
\hline Castellana & 27 & 0.0074 & 24 & 0.986 & 36 & - & 1 & - \\
\hline Manchega & 26 & 0.0098 & 23 & 0.991 & 39 & 0.08 & 0.92 & - \\
\hline Rasa Aragonesa & 16 & 0.0086 & 16 & 1 & 30 & - & 1 & - \\
\hline Segureña & 16 & 0.0066 & 16 & 1 & 21 & - & 1 & - \\
\hline Serra da Estrela & 21 & 0.0092 & 19 & 0.990 & 37 & 0.05 & 0.95 & - \\
\hline \multicolumn{9}{|l|}{ MERINO TRUNK } \\
\hline Spanish Merino & 18 & 0.0063 & 16 & 0.987 & 22 & - & 1 & - \\
\hline Merino Branco & 16 & 0.0141 & 16 & 1 & 41 & 0.12 & 0.88 & - \\
\hline Merino de Beira Baixa & 16 & 0.0055 & 16 & 1 & 22 & - & 1 & - \\
\hline Merino Preto & 15 & 0.0062 & 14 & 0.990 & 20 & - & 1 & - \\
\hline \multicolumn{9}{|l|}{ IBERIAN TRUNK } \\
\hline Montesina & 17 & 0.0133 & 17 & 1 & 42 & 0.06 & 0.88 & 0.06 \\
\hline Ojalada & 16 & 0.0101 & 14 & 0.983 & 32 & - & 0.94 & 0.06 \\
\hline \multicolumn{9}{|l|}{ UNASSIGNED } \\
\hline Bordaleira E.D.M. & 19 & 0.0043 & 10 & 0.918 & 17 & - & 1 & - \\
\hline Merino de Grazalema & 16 & 0.0096 & 15 & 0.992 & 33 & 0.06 & 0.94 & - \\
\hline \multicolumn{9}{|l|}{ FOREIGN SHEEP } \\
\hline Assaf & 15 & 0.0039 & 10 & 0.933 & 12 & - & 1 & - \\
\hline Awassi & 24 & 0.0243 & 22 & 0.993 & 53 & 0.25 & 0.50 & 0.25 \\
\hline Lacaune & 30 & 0.0060 & 25 & 0.986 & 33 & - & 1 & - \\
\hline Milchschaf & 16 & 0.0150 & 13 & 0.975 & 31 & 0.25 & 0.75 & - \\
\hline Ossimi & 17 & 0.0137 & 12 & 0.956 & 31 & 0.18 & 0.82 & - \\
\hline Rahmani & 18 & 0.0154 & 10 & 0.850 & 41 & 0.11 & 0.78 & 0.11 \\
\hline
\end{tabular}

7 flocks per breed. The studied Iberian breeds represented the four morphological trunks previously described, while two breeds were considered as unassigned since there is no agreement about their origins.

The foreign sheep were the following: European Lacaune and Milchschaf sheep (from France and Germany, respectively), Egyptian Ossimi and 
Rhamani, and two breeds of Middle Eastern origin, Awassi and Assaf sheep. Of these latter breeds, the Awassis sampled originated in Israel, while the Assafs came from the population now called Spanish Assaf, since they are the result of upgrading crossing of local Iberian breeds (from both Churro and Entrefino types) with the Assaf population obtained in Israel.

\subsection{Methodology}

Genomic DNA was obtained from blood or semen using the "salting out" procedure and the D-loop containing region between sites 15437 and 16616 was amplified. Primers were designed from the published ovine sequence $O$. aries [AF010406] [9]: tRNA-proline (5'-CAGTGCCTTGCTTTGGTTAAGC-3') and tRNA-phenylalanine (5'-CACCATCAACCCCAAAGCTGAAG-3'). The PCR mixture $(10 \mu \mathrm{L})$ was as follows: $30 \mathrm{ng}$ of DNA, $2 \mathrm{mM} \mathrm{MgCl} 2,2.5$ pmoles of each primer, $2 \mathrm{mM}$ of each dNTP, $0.5 \mathrm{U}$ Taq DNA polymerase and $1 \mu \mathrm{L}$ of $10 \mathrm{X}$ PCR Buffer. Sequences were determined using two additional internal primers: BDG (5'-CATCTGCTTCTTTCTTCAGGGCCATC-3') and HC3 (5'-TGGACTCAGCTATGGCCGTC-3'). Both strands of DNA were cycle sequenced on a GeneAmp9700 thermal cycler (Applied Biosystems) and subsequently analysed in an ABIPRISM 377 DNA sequencer (Applied Biosystems) using the Sequencing Analysis 3.7 software.

Sequence alignment of the $663 \mathrm{bp}$ fragment (after excluding the $75 \mathrm{nt}$ tandem-repeat element) was achieved by means of the DNA alignment software (Fluxus technology, http://www.fluxus-engineering.com/). Alignment gaps were checked by eye and subsequent complete deletion. A pairwise distance matrix between mtDNA sequences was computed using the nucleotide p-distance [12], and a neighbour-joining (NJ) tree constructed on the basis of these distances using the MEGA 3.0 software [10]. A median joining network [3] was drawn from haplotypes using the program Network 4.1.0.9 (www.fluxus-engineering.com). As references of ovine types B, A and C, the three sequences used were the most frequent haplotypes identified for each of the three mtDNA types in Turkish sheep by Pedrosa et al. [13] and available in GenBank (O. aries B, A and C referenced as DQ097431, DQ097451 and DQ097457, respectively).

Indices of sequence variation and haplotype structure were calculated using the DnaSP 4.00 program [15], including nucleotide diversity $(\pi)$, number of haplotypes (nh), haplotype diversity (Hd) and number of polymorphic sites $(S)$. An analysis of molecular variance (AMOVA) was computed to test 
significant differences between breeds and trunks, using ARLEQUIN 3.01 [7]. Sources of variation were considered in a single model: among trunks (unassigned breeds were not included in the analysis), among breeds - within trunks - and within breeds. Finally, a multidimensional scaling representation of breeds was derived from uncorrected pairwise $p$-distances using program SPSS 13.01 [19]; the stress value was 0.19.

\section{RESULTS}

A total of 360 haplotypes were identified involving 120 segregating sites (haplotypes are available in GenBank accession no. DQ790890-DQ791249). The neighbour-joining tree obtained from mtDNA haplotypes of Iberian and foreign sheep is presented in Figure 1, three separate clusters being evident in the figure representing haplogroups $\mathrm{B}, \mathrm{A}$ and $\mathrm{C}$ (reference sequences are indicated). A similar tree (not shown) was obtained from Iberian sheep only. Most Iberian sequences were included in cluster B, while seven individuals exhibited mtDNA type A and two animals showed type C. The median-joining network obtained from Iberian haplotypes is shown in Figure 2. Haplotypes from breeds belonging to the Merino trunk appear shaded. It is to be noticed that the reference sequence of $O$. aries B matched the most frequent haplotype. The frequencies of mtDNA types are summarised in Table I and illustrated in Figure 3. Nucleotide diversity (Tab. I) indicated the greatest variability in Awassis of all the breeds analysed (0.0243), together with a high frequency of individuals with mtDNA types $\mathrm{A}$ and $\mathrm{C}$ (apart from the common type B). Among the Iberian sheep, the two breeds belonging to the so-called Iberian trunk (Ojalada and Montesina) showed great nucleotide diversity (0.0101 and 0.0133) and of these, Montesinas were the only Iberian sheep with individuals representing each of the three mtDNA lineages, a pattern only exhibited elsewhere in this study by Awassi and Rahmani sheep.

Among the Merino populations, haplotypes A were identified only in the Merino Branco breed, whereas in the others only type B was observed. This trunk exhibited the widest range of variation in nucleotide diversity ( 0.0055 to 0.0141), the latter value proving the greatest among all Iberian sheep.

Within the Entrefino trunk, mtDNA type A was found in two breeds (Manchega and Serra de Estrela sheep) out of the six populations studied. Finally, sheep from the Churro trunk appeared among the least variable (nucleotide diversities from 0.0047 to 0.0068 ) and all mtDNA sequences were of type B. 


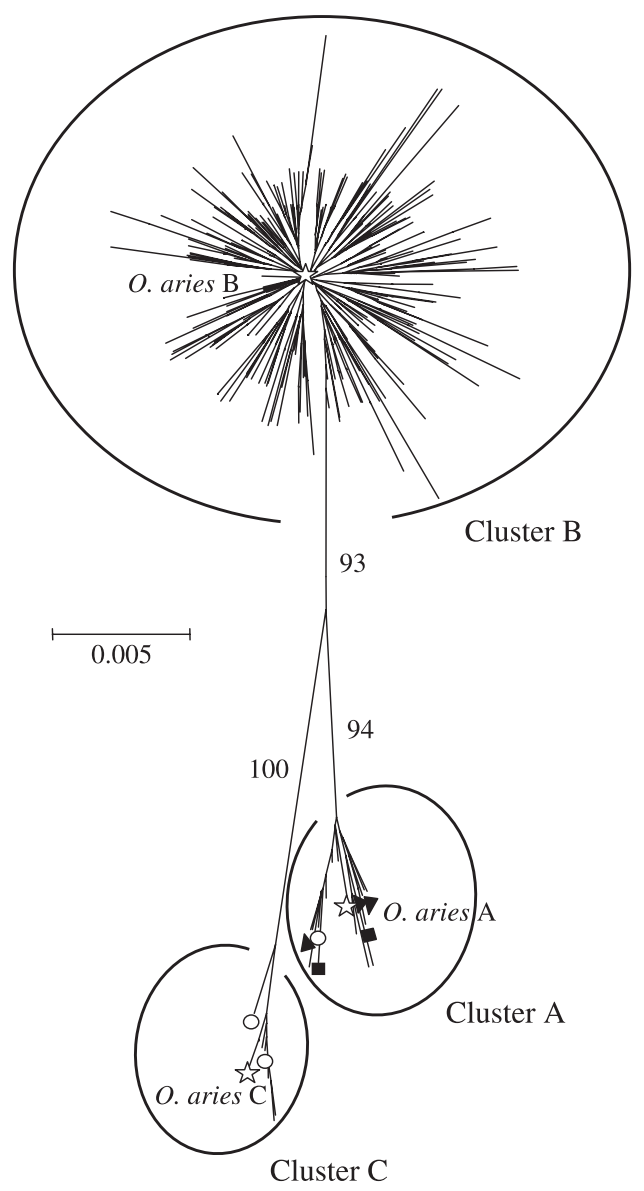

Figure 1. Neighbour-joining tree of Iberian and foreign sheep mtDNA sequences. Bootstrap supporting values are shown on the nodes. Iberian haplotypes grouped in clusters A or C are indicated as follows: $\Delta$ Entrefino trunk, $\mathbf{a}$ Merino trunk, $\bigcirc$ Iberian trunk. Haplotypes indicated by a star are reference sequences of $O$. aries B [DQ097431], A [DQ097451] and C [DQ097457].

The results from the AMOVA analysis revealed significant differences among breeds but not among trunks, most variability being found within populations (92\% within and $8 \%$ among breeds). Figure 4 shows the multidimensional scaling representation of Iberian breeds based on nucleotide pairwise distances. Ten out of the 19 breeds appear as very closely related in this representation, including three Merino populations. The Merino Branco population and the two breeds belonging to the so-called Iberian trunk (Montesina and Ojalada sheep) are noticeable among the clearly separated breeds. 
Mitochondrial diversity in Iberian sheep

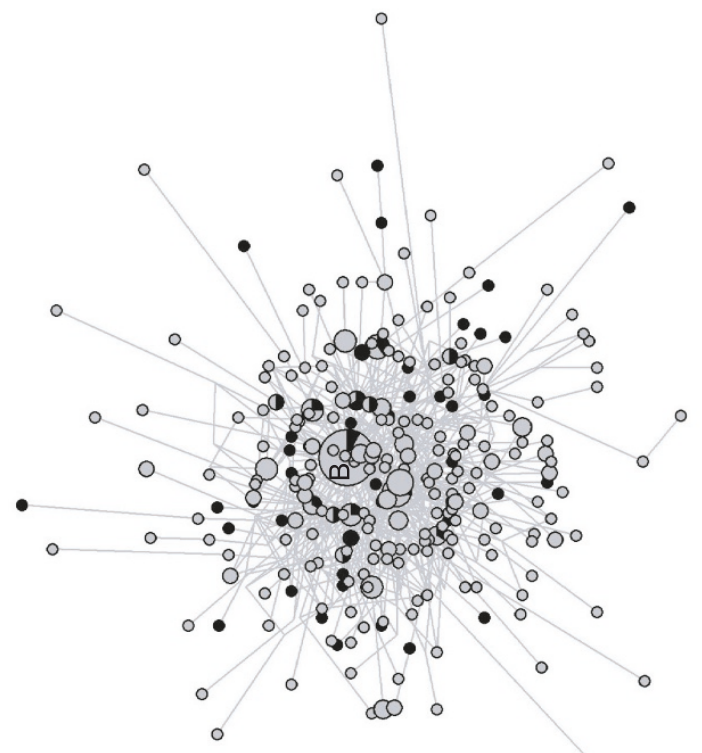

ส

๑

a

ت્ّ

:

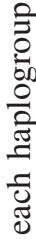

4

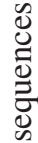

$\frac{8}{4}$

忘

$\varangle^{\circ}$

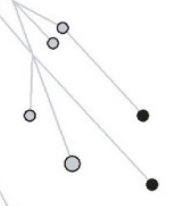

$\frac{8}{\infty}$

:

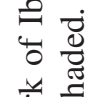

क्ष

䒕

$0^{\circ}$ 


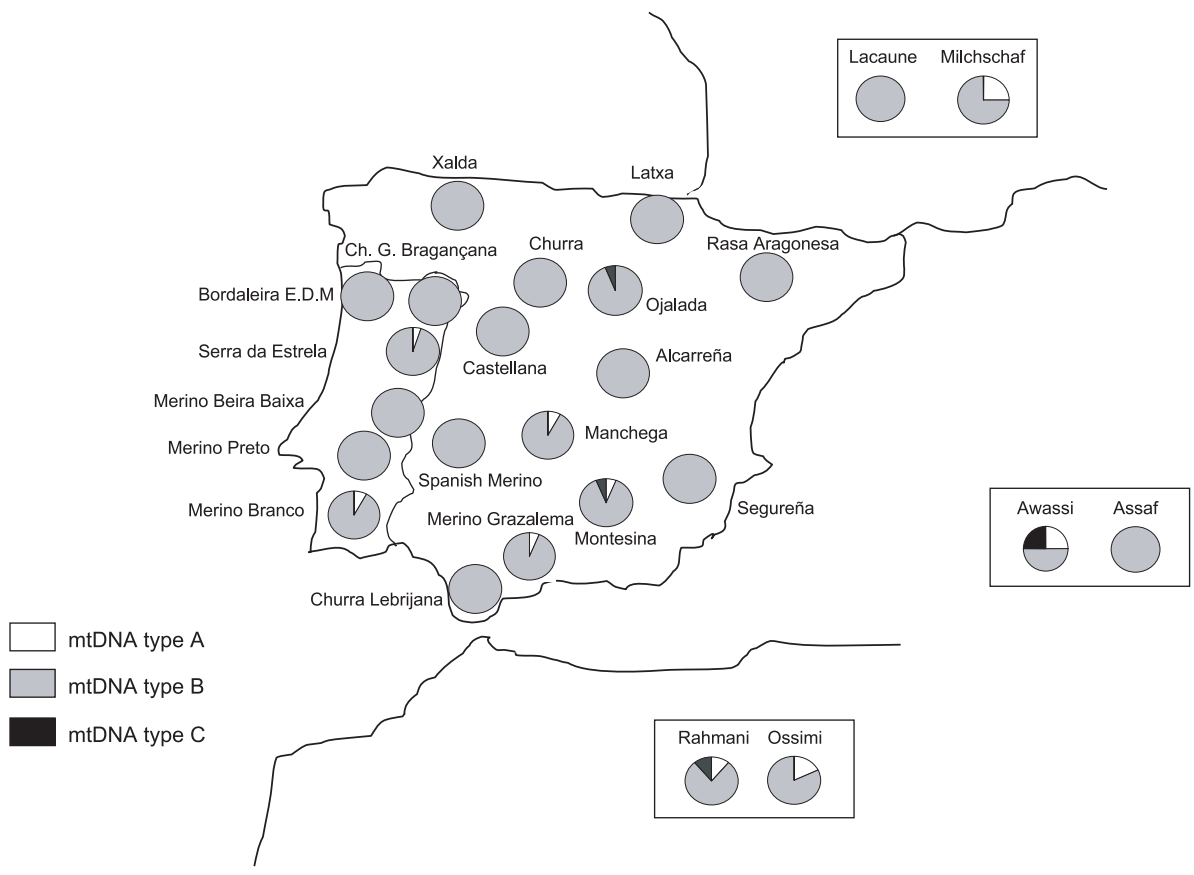

Figure 3. Approximate geographical distribution of Iberian sheep. The proportion of mtDNA types in each breed is illustrated.

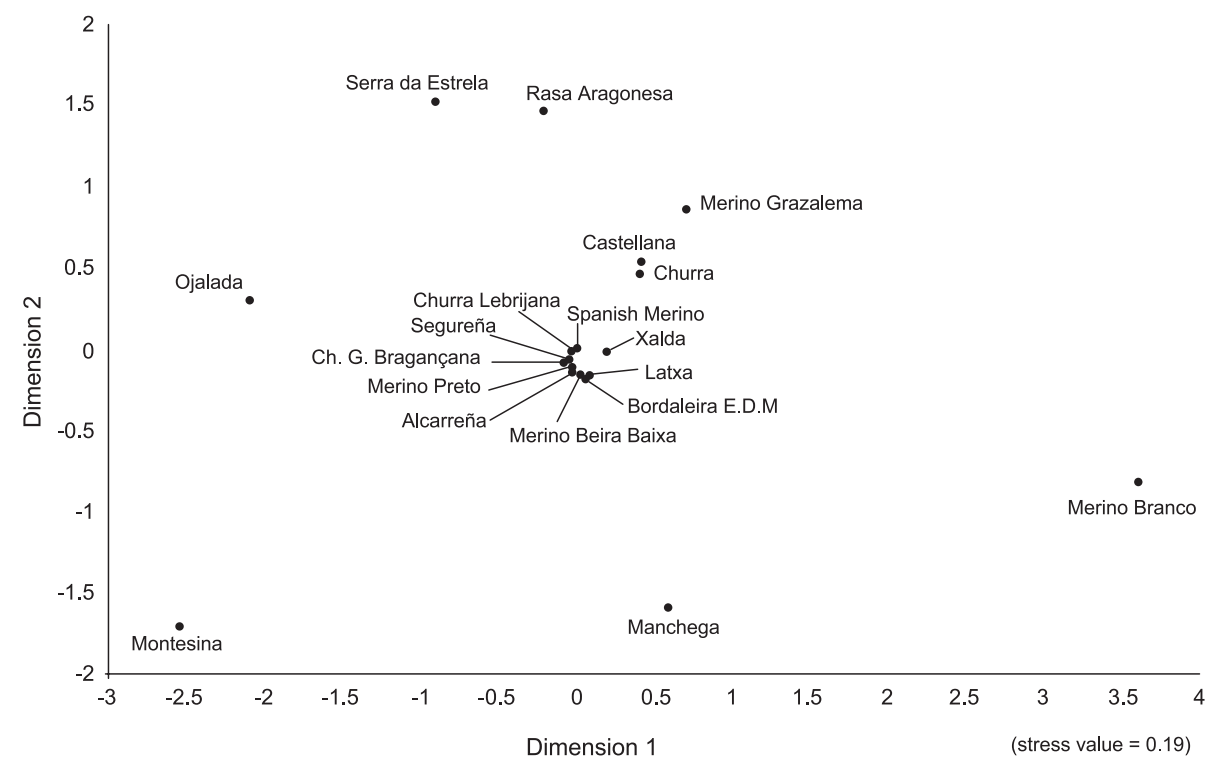

Figure 4. Multidimensional scaling representation of pairwise distances between Iberian sheep breeds. 


\section{DISCUSSION}

Analyses of mitochondrial DNA sequences revealed high variability in Iberian sheep and the presence of three out of the four maternal lineages identified so far in that species. In accordance with results available from European breeds [9], mtDNA haplotype B clearly predominated over other mitochondrial sequences. The presence of certain Iberian individuals showing the Asian haplotype, A, was not unexpected, in line with its presence in European sheep (e.g. Milchschaf breed in our study), and in accordance with a high gene flow between Asian and European sheep [11]. However, the most relevant result from Iberian exploration was the identification of two individuals showing haplotype $\mathrm{C}$. The recently reported type $\mathrm{C}$ has proven more frequent in Anatolian sheep [13] than in other Asiatic breeds [5, 8,20], and within Europe it has been found, so far, only in Portugal [14].

The results given here for Israeli Awassi sheep are in accordance with a greater presence in Near Eastern sheep and those from the Egyptian Rahmani breed, known to derive from Morkaraman sheep (found in Turkey and Iran), were also in agreement with this information, Rahmanis also showing the three mtDNA types. For their part, the results reported here for the so-called Spanish Assaf sheep (obtained through upgrading crossing of Spanish sheep with Assaf males) reflect their mitochondrial similarity with Iberian sheep as revealed by the unique presence of mtDNA type B.

The origin of modern Iberian sheep is known to be very complex since they are the result of different influences of livestock accompanying the multiple invasions that reached the Iberian Peninsula throughout history. It has been suggested that domestic ovines originated in Asia, first reached the Peninsula along the eastern Mediterranean coast. Later, other ovines arrived through distinct immigrations crossing the Pyrenees (from the north) and also via the Mediterranean coast.

As already indicated, current Iberian sheep are classified into four groups of breeds or trunks based on morphological characteristics (mainly their wool type) together with available historical information. However, there is no absolute agreement about their origin and possible interrelationships among each other. In this regard, our study did not detect a significant subdivision in trunks on a maternal inheritance basis, most variability ( $>90 \%)$ being found within populations. This result was also evident from the multidimensional scaling representation of breeds (Fig. 4), where no clustering according to trunks can be observed while certain breeds within a trunk appear as clearly separated from others (e.g. Merino Branco). 
Merinos are the most internationally known Iberian sheep. Examination of the network representation (Fig. 2) indicates that maternal variability found within Merinos represents a small part of the mitochondrial diversity identified in Iberian sheep as a whole. All Merinos were of mtDNA type B except for two animals of the Merino Branco breed which exhibited haplotypes A. Since this breed is known to have been crossed throughout the 20th century with certain improved European Merinos such as French Rambouillet sheep [18], they cannot be considered as strictly representative of pure Merinos. The differentiation of this breed from the rest of Merinos was also evident from the multidimensional scaling plot (Fig. 4). This differentiation also appeared when rare haplogroups were not considered in the analysis.

Nucleotide diversity in the other three Merino populations (0.0055-0.0063) was intermediate when compared with the rest of Iberian sheep. Previous information reported by us from nuclear markers in the population designated here as Spanish Merinos had indicated greater nuclear diversity than in other Iberian sheep [1]. However, data from mitochondrial DNA seems to indicate that this is not the case when maternal inheritance is analysed, their great overall diversity probably having originated via males.

The origin of the unassigned Merino de Grazalema breed has yet to be clarified [6]. They were previously considered a subtype of the Spanish Merino breed, but more recently it has been suggested that they resulted from a Spanish Merino $\times$ Churro crossing, on the basis of the intermediate morphological characteristics. Our finding in Merino de Grazalema of a mtDNA haplotype A identical to that identified in the closely located Montesina breed (Iberian trunk), while all mtDNA sequences identified in Spanish Merino breed were of type B, suggests that Merino de Grazalema shares some recent ancestry with the Iberian trunk.

As for the Churro trunk, a major influence from coarse-wool Central European populations has been postulated. These sheep, which are mainly reared in the northern and central parts of the Iberian Peninsula, appeared in our study as fairly uniform as far as their maternal origin is concerned. In this regard it can be seen from Figure 4, that Churro was the only trunk for which all breeds appeared close in the multidimensional scaling plot, while they showed rather low nucleotide diversities and exhibited only mtDNA type B (Tab. I).

Different hypotheses have been proposed regarding the origin of sheep from the Entrefino trunk. Certain authors consider these breeds as the result of Merino $\times$ Churro crossings [22], whereas others claim an independent origin [17], suggesting a major influence received via the Mediterranean coast. Previous studies through microsatellite loci on the same animals [1], had led 
to the conclusion that Entrefinos must have been influenced by the Churro trunk, since no clear separation was evident between the two trunks on a nuclear basis. The results described here for mtDNA suggest certain differences in the maternal origin of sheep from both trunks. A more heterogeneous maternal origin seems to characterise sheep from the Entrefino trunk as suggested by breed representation in Figure 4, since three out of the six Entrefino populations (Serra da Estrela, Rasa Aragonesa and Manchega) appeared separated among each other and from the others (Castellana, Alcarreña and Segureña). Also, the identification of the mtDNA Asian haplotype or type A in two Entrefino breeds, although with a very low frequency was also remarked.

Finally, the most outstanding results from our study were those concerning the so-called Iberian trunk, a small group of animals of marked rusticity now reared isolated in certain mountainous areas [6]. Sánchez and Sánchez [17] pay special attention to this group, suggesting it represents the most ancient Iberian sheep type originating from the first ovine populations that reached the Iberian Peninsula. They postulate that these original populations, firstly extending over a wide area of the Peninsula, were progressively substituted by more productive breeds with the arrival of later immigrations, the remaining animals being currently found in very restricted areas. The results reported here on mitochondrial DNA are quite in accordance with a related origin for the two breeds (Montesina and Ojalada) representing this trunk since both of them exhibited rare type $C$, although certain divergence was evident from Figure 4. Since these two populations are isolated from each other in widely separated parts of the Iberian Peninsula, a related origin of the two breeds seems more likely to explain our results than a more recent maternal gene flow. Pereira et al. [14] suggested that the presence of haplotype C in the Iberian Peninsula might have its origin in the Arab influence (from 711 AD onwards). However, the peculiarity of the Iberian breeds in which type $\mathrm{C}$ was identified in our study suggests a different scenario with a much earlier arrival of this type in the Peninsula. Moreover, ovine reproductions found in primitive Iberian excavations dated c. 300-200 BCE with a similar morphology to that of modern Iberian trunk sheep [17] support an early presence of these sheep in the Iberian Peninsula. Further detailed investigations including African sheep need to be done to clarify where and when these haplotypes came to the Peninsula.

As a general conclusion, we may indicate that the results described here for mitochondrial DNA confirm the high diversity present in Iberian livestock as a result of its peculiar geographical situation. These data are a valuable complement to previous information from nuclear markers as well as from 
morphological and historical data, proving very useful in the analysis of the origin of the different Iberian sheep.

\section{ACKNOWLEDGEMENTS}

This work was supported by Spanish-INIA-RZ02-015 and INIA-RZ03-019 grants. We thank Dr. M. El-Zarei for kindly providing Ossimi and Rahmani samples.

\section{REFERENCES}

[1] Arranz J.J., Bayón Y., San Primitivo F., Genetic relationships among Spanish sheep using microsatellites, Anim. Genet. 29 (1998) 435-440.

[2] Arranz J.J., Bayón Y., San Primitivo F., Differentiation among Spanish sheep breeds using microsatellites, Genet. Sel. Evol. 33 (2001) 529-542.

[3] Bandelt H.J., Forster P., Rohl A., Median-joining networks for inferring intraspecific phylogenies, Mol. Biol. Evol. 16 (1999) 37-48.

[4] Bruford M.W., Bradley D.G., Luikart G., DNA markers reveal the complexity of livestock domestication, Nature Rev. Genet. 4 (2003) 900-910.

[5] Chen S.Y., Duan Z.Y., Sha T., Kiangyu J., Wu S.F., Zhang Y.P., Origin, genetic diversity and population structure of Chinese domestic sheep, Gene 376 (2006) 216-223.

[6] Esteban C., Razas Ganaderas Españolas Ovinas, Ministerio de Agricultura, Pesca y Alimentación, Spain, 2003.

[7] Excoffier L., Laval G., Schneider S., Arlequin ver. 3.0: An integrated software package for population genetics data analysis, Evol. Bioinform. Online 1 (2005) $47-50$.

[8] Guo J., Du L.X., Ma Y.H., Guan W.J., Li H.B., Zhao Q.J., Li X., Rao S.Q., A novel maternal lineage revealed in sheep (Ovis aries), Anim. Genet. 36 (2005) 331-336.

[9] Hiendleder S., Mainz K., Plante Y., Lewalski H., Analysis of mitochondrial DNA indicates that domestic sheep are derived from two different ancestral maternal sources. No evidence for contributions from urial and argali sheep, J. Hered. 89 (1998) 113-120.

[10] Kumar S., Tamura K., Nei M., MEGA3: Integrated software for molecular evolutionary genetics analysis and sequence alignment, Briefings in Bioinformatics 5 (2004) 150-163.

[11] Meadows J.R.S., Li K., Kantanen J., Tapio M., Sipos W., Pardeshi V., Gupta V., Calvo H., Whan V., Norris B., Kijas J.W., Mitochondrial sequence reveals high levels of gene flow between breeds of domestic sheep from Asia and Europe, J. Hered. 96 (2005) 494-501.

[12] Nei M., Kumar S., Molecular Evolution and Phylogenetics, Oxford University Press, New York, 2000. 
[13] Pedrosa S., Uzun M., Arranz J.J., Gutiérrez-Gil B., San Primitivo F., Bayón Y., Evidence of three maternal lineages in Near Eastern sheep supporting multiple domestication events, Proc. R. Soc. Lond. B 272 (2005) 2211-2217.

[14] Pereira F., Davis S.J.M., Pereira L., McEvoy B., Bradley D.G., Amorin A., Genetic signatures of a Mediterranean influence in Iberian Peninsula sheep husbandry, Mol. Biol. Evol. 23 (2006) 1420-1426.

[15] Rozas J., Sánchez-del-Barrio J.C., Messeguer X., Rozas R., DnaSP, DNA polymorphism analyses by the coalescent and other methods, Bioinformatics 19 (2003) 2496-2497.

[16] Ryder M.L., Sheep, in: Mason I.L. (Ed.), Evolution of domesticated animals, Longman, London and New York, 1984, pp. 63-85.

[17] Sánchez A., Sánchez M.C., Razas Ovinas Españolas, Ministerio de Agricultura, Pesca y Alimentación, Madrid, 1986.

[18] Sobral M., Antero C., Borrego J.D., Domingos A.N., Recursos Genéticos. Raças Autóctones. Espécies Ovina e Caprina, Associaçao de Criadores de Ovinos do Sul, Portugal, 1991.

[19] SPSS $^{\circledR}$ for Windows, Rel. 13.0.1. 2004. Chicago, SPSS ${ }^{\circledR}$ Inc.

[20] Tapio M., Marzanov N., Ozerov M., Cinkulov M., Gonzarzenko G., Kiselyova T., Murawski M., Viinalass H., Kantanen J., Sheep mitochondrial DNA variation in European, Caucasian and Central Asian areas, Mol. Biol. Evol. DOI: $10.1093 / \mathrm{molbev} / \mathrm{msl043.}$

[21] Wood N.J., Phua S.H., Variation in control region sequence of the sheep mitochondrial genome, Anim. Genet. 27 (1996) 25-33.

[22] Yanes J.E., Catálogo de Razas Autóctonas de Castilla y León, España-Región Norte de Portugal, Fundacao Rei Afonso Henriques, Spain, 2002. 